\title{
EFFECTS OF EXOGENOUS RSRHA2B GENE ON KEY ENZYME ACTIVITIES AND EXPRESSION OF RELATED GENES IN THE GRAIN FILLING STAGE OF WHEAT (TRITICUM AESTIVUM L.)
}

\author{
LI, D. B." - LYU, G. Z." - JIANG, Y. M. - NIU, H. B. - WANG, X. - YIN, J. \\ National Engineering Research Center for Wheat, State Key Laboratory of Wheat and Maize \\ Crop Science, Collaborative Innovation Center of Henan Grain Crop, Henan Agricultural \\ University, Zhengzhou 450002, China \\ *Corresponding author \\ e-mail:xmzxyj@126.com; phone: +86-371-6355-8203 \\ ${ }^{\#}$ These authors contributed equally to this work.
}

(Received $26^{\text {th }}$ Jun 2019; accepted $10^{\text {th }}$ Sep 2019)

\begin{abstract}
The influence of pure transgenic wheat strain 1477 and Zhengmai 9023 were used to explore the effect of exogenous RsRHA2b gene introduction on the activity of key enzymes for starch synthesis and protein synthesis and the expression of related genes in transgenic wheat during filling period. The results showed that the introduction of exogenous $R S R H A 2 b$ increased the activity of adenosine diphosphate glucose pyrophosphorylase (AGPP), granular starch synthase (GBSS), starch branching enzyme (SBE), soluble starch synthase (SSS) and glutamate synthase (GOGAT), and decreased the activity of glutamyl ammonia synthase (GS). Exogenous RsRHA2b promoted the expression of YTH311, YTH611, YTH1065, YTH2437, YTH2438, YTH2456, YTH2496 and YTH3049, and inhibited the expression of $Y T H 2433$. These results indicated that the change in carbon and nitrogen metabolic key enzyme activity and the effect on related gene expression caused by the introduction of exogenous $R s R H A 2 b$ gene may be the main cause of the increased resistance to ear germination of $R s R H A 2 b$ transgenic wheat.
\end{abstract}

Keywords: starch synthase, protein synthase, interacting proteins, gene expression, pre-harvest sprouting

\section{Introduction}

Pre-harvest sprouting (PHS), a problem caused by environmental and genetic factors, affected wheat (Triticum aestivum L.) production in mature stage. About $85 \%$ of the wheat producing areas in China are susceptible to ear germination. After sprouting, the yield and quality of wheat will be reduced, and even food value and processing will be negativly affected, and the number of usable seeds will decrease. Grain traits, including grain maturity and size, seed coat color and thickness, can affect spike germination of wheat to varying degrees.

The main component of wheat grain yield is endosperm starch, followed by endosperm protein. The formation of wheat grain yield is essentially a process of starch and protein synthesis and accumulation in endosperm. Therefore, carbon metabolism and nitrogen metabolism are two main metabolic pathways in wheat grain development. Both of them are interrelated to each other to complete the material accumulation of grains, which determines the quality of grains.

There are many enzymes involved in starch synthesis. It is generally believed that sucrose synthase (SS), ADPG pyrophosphatase (AGPase), starch synthase (SSS and GBSS) and amylopectin branching enzyme (SBE) are key enzymes in the process of starch synthesis and metabolism, and play an important regulatory role in the synthesis 
and accumulation of starch in wheat grains (Yang et al., 2004; Baroja-Fernández et al., 2003; Emes et al., 2003). ADPG-PPase and SSS were positively correlated with total starch and amylopectin accumulation rate (Zhao et al., 2004), while GBSS was positively correlated with amylose accumulation rate (Wang et al., 2003; Li et al., 2001). Protein quality of wheat grain is one of the important indexes for evaluating wheat quality (Wang et al., 2001; Pan and Yu, 2002). The main pathway of nitrogen assimilation in plants is directly involved in the synthesis and transformation of amino acids after nitrate reduction to ammonium. Nitrate reductase (NR), glutamine synthase (GS), glutamine synthase (GOGAT), asparagine transaminase (AspAT) and other key enzymes are involved in catalysis and regulation. This study focused on GS and GOGAT enzymes.

AtRHA2b gene of Arabidopsis thaliana encodes E3 ubiquitination ligase, which plays an important role in ABA signal transmission and stress. Cloning and characterization of a wheat RING finger gene TaRHA2b whose expression is upregulated ( $\mathrm{Li}$ et al., 2019). Overexpression of AtRHA2b leads to ABA-related phenotypes, such as seed germination and seedling sensitivity to ABA. The genetic distance between radish and Arabidopsis is very close, so RsRHA2b gene in radish was used for genetic improvement in wheat to avoid the phenomenon of cohomology inhibition in transgenic plants. The transgenic $R s R H A 2 b$ wheat was successfully created by agrobacterium-mediated method at the early stage of seed germination. Compared with the Zhengmai 9023, the resistance of transgenic strains to PHS was significantly enhanced. The proteins interacting with RHA2b were selected by yeast two-hybrid assay. The information of candidate interacting proteins is shown in Table 1, including SBE, nitrite reductase, CBL, DDT domain protein, auxin effector factor 1, E3 UFM1 protein ligase 1 homologue, small $G$ protein, AP2/EREBP protein and AGAP. The study of RHA2b interacting proteins is conducive to the study of the mechanism of the $R H A 2 b$ gene.

Table 1. Summary of related genes at the grain filling period (from NCBI database)

\begin{tabular}{c|c|c|c}
\hline Gene & $\begin{array}{c}\text { Accession number } \\
\text { (Barley) }\end{array}$ & $\begin{array}{c}\text { Accession number } \\
\text { (Wheat) }\end{array}$ & Function \\
\hline$Y T H 311$ & FN179383.1 & BT008928.1 & SBE starch branching enzyme \\
YTH611 & AK363669.1 & AK331993.1 & Nitrite reductase \\
$Y T H 1065$ & AK252590.1 & AK332453.1 & CBL \\
$Y T H 2433$ & AK372028 & HX078550.1 & DDT domain protein \\
$Y T H 2437$ & AK358361.18 & CK206694.1 & Auxin effector factor 1 \\
$Y T H 2438$ & AK364219.1 & AK332649.1 & E3 UFM1 protein ligase 1 homologue \\
$Y T H 2456$ & AK251632.1 & GU452718.1 & Small G protein \\
$Y T H 2496$ & HQ647352.1 & FJ560496.1 & AP2/EREBP protein \\
$Y T H 3039$ & AK372413.1 & AK331446.1 & AGAP gene \\
\hline
\end{tabular}

In order to reveal the regulatory effect and mechanism of RsRHA2b gene on starch and protein formation in wheat grains, the key enzymes and gene expression of starch synthesis, key enzymes of protein synthesis and gene expression in transgenic and control wheat grains at grain filling stage were analyzed. The aim of this study was to provide a basis for further application of genetically modified wheat (GM) resistant to PHS in production. 


\section{Materials and methods}

The elite Chinese bread wheat cultivar Zhengmai 9023, ahexaploid wheat cultivar with weak resistance to PHS, is widely cultivated in Henan Province. Exogenous RsRHA2b gene was introduced into wheat "zhengmai 9023 " by agrobacterium-mediated method in the early germination stage. After six successive generations of planting, and combined with basta resistance screening, PCR, RT-PCR and southern-blot analysis, the transgenic strain 1477 with stable inheritance of exogenous $R s R H A 2 b$ gene and strong resistance to ear germination was screened. Transgenic lines and non-transgenic control variety Zhengmai 9023 were planted in the Science and Education Demonstration Park of Henan Agricultural University during the growth season from 2013 to 2014.

\section{Determination of enzyme activity in wheat starch synthesis}

The single spike with the same flowering date and the same panicle size was selected. Starting from the $5^{\text {th }}$ day after flowering, samples were taken every $5 \mathrm{~d}$ for a total of 6 times. Two grains labeled at the base of spikelet from $4^{\text {th }}$ to $10^{\text {th }}$ spikes were selected. every time take 200 grain, put into liquid nitrogen frozen $30 \mathrm{~min}$, buy $-80^{\circ} \mathrm{C}$ refrigerator, used for determination of enzyme activity and gene expression. Key enzymes for starch synthesis include ADPG, SSS, GBSS and SBE. Cheng Fangmin's method of extracting crude enzymes from wheat grains was used as reference (Cheng et al., 2001). The activity changes of AGPP, SSS and GBSS were determined by Nakamura's method (Nakamura et al., 1989). The activity of SBE was determined by Li Taigui's method (Li et al., 1997). The steps of these methods are optimized as follows.

\section{Determination of $A D P G$}

Take $20 \mu \mathrm{L}$ enzyme crude extract, $110 \mu \mathrm{L}$ reaction solution was added (the final concentration of the reaction solution was $100 \mathrm{mM}$ Hepes- $\mathrm{NaOH}(\mathrm{pH} 7.4), 1.2 \mathrm{mM}$ ADPG, $3 \mathrm{mM} \mathrm{PPi}, 5 \mathrm{mM} \mathrm{MgCl} 2$ and $4 \mathrm{mM}$ DTT); $30{ }^{\circ} \mathrm{C}$, reaction for $20 \mathrm{~min}, 30 \mathrm{~s}$ termination reaction in the boiling water; $10000 \times \mathrm{g}, 10 \mathrm{~min}$, take $100 \mu \mathrm{L}$ supernatant, add 5.2 $\mu \mathrm{L}$ supernatant to colorimetric solution (5.76 mM NADP, 0.08 unit Pglucomutase (phosphoglucose mutase), 0.07 unit G6p-dehydrogenase); $30{ }^{\circ} \mathrm{C}$ reaction for $10 \mathrm{~min}$, determination $\mathrm{OD}_{340 \mathrm{~nm}}$ value; The activity of ADPG pyrophosphorylase was calculated based on the increase of $\mathrm{OD}_{340 \mathrm{~nm}}$ value, and the unit was nmol/1000seeds min.

\section{Determination of SSS and GBSS}

Weigh the wheat seeds in the mortar, add liquid nitrogen and grind to powder; transfer to the centrifugal tube, and add appropriate amount of extract, containing 100 $\mathrm{mM}$ Tris- $\mathrm{HCl}$ (pH 7.5),8 mM MgCl2, 2 mM EDTA, 12.5\% (V/V) glycerin, $1 \%$ (W/V) PVP-40, $50 \mathrm{mM}$ d-mercapto ethanol; $10000 \times \mathrm{g}, 4{ }^{\circ} \mathrm{C}$ centrifugal $30 \mathrm{~min}$, then collect the clear liquid in an ice bath, as crude enzyme liquid for later use; the precipitate was washed twice with $1 \mathrm{~mL}$ extract and then suspended in $2 \mathrm{~mL}$ extraction medium for GBSS activity measurement; the $20 \mu \mathrm{L}$ enzyme crude extract was added to $36 \mu \mathrm{L}$ reaction solution I (the final concentration of the reaction solution was $50 \mathrm{mM}$ Hepes$\mathrm{NaOH}$ (pH 7.4), $1.6 \mathrm{mM}$ ADPG, $0.7 \mathrm{mg}$ amylopectin, $15 \mathrm{mM}$ DTT); $30{ }^{\circ} \mathrm{C}$, reaction for $20 \mathrm{~min}, 30 \mathrm{~s}$ termination reaction in the boiling water, cooled in the ice bath; add $20 \mu \mathrm{L}$ reaction solution II, containing $50 \mathrm{mM}$ HEPES-NaOH (pH 7.4), 4 mM PEP, $200 \mathrm{mM}$ 
$\mathrm{KCl}, 10 \mathrm{mM} \mathrm{MgCl} 2,1.2$ unit pyruvate kinase; reaction after $20 \mathrm{~min} 30{ }^{\circ} \mathrm{C}$, boiling water termination reaction in the $30 \mathrm{~s} ; 10000 \times \mathrm{g}, 4{ }^{\circ} \mathrm{C}$ centrifugal $30 \mathrm{~min}$, the supernatant $(60 \mu \mathrm{L})$ and $43 \mu \mathrm{L}$ reaction solution (III), $50 \mathrm{mM}$ HEPES-NaOH (pH 7.4), $10 \mathrm{mM}$ glucose, $20 \mathrm{mM} \mathrm{MgCl} 2,2 \mathrm{mM}$ NADP, 1.4 unit hexokinase, 0.35 unit G6pdehydrogenase; $30{ }^{\circ} \mathrm{C}$ reaction after $10 \mathrm{~min}$, measuring $\mathrm{OD}_{340 \mathrm{~nm}}$ value changes, the unit is nmol 1000 seeds min. The crude enzyme solution boiled at $20 \mu \mathrm{L}$ was used as the control.

\section{Determination of SBE}

The wheat seeds were placed in a mortar, add liquid nitrogen and grind to powder, transfer to centrifugal tube; add $0.05 \mathrm{M}$ citric acid buffer (PH 7.0) (diluted with $0.2 \mathrm{M}$ citric acid buffer by 4 times); $4{ }^{\circ} \mathrm{C}, 23203 \times \mathrm{g}$ under centrifugal $20 \mathrm{~min}$, supernatant is the thick enzyme fluid; take $1 \mathrm{~mL}$ crude enzyme solution, add $0.2 \mathrm{M}$ citric acid buffer $1 \mathrm{~mL}$ (pH 7.0), $0.1 \mathrm{M}$ EDTA $0.5 \mathrm{~mL}, 0.75 \%$ soluble starch $0.5 \mathrm{~mL}$, according to the same procedure to prepare another as the control; experimental group $40 \mathrm{~min}$ in $37{ }^{\circ} \mathrm{C}$ water bath heating, control placed on ice, add $4 \mathrm{~mL} \mathrm{10 \%} \mathrm{TCA} \mathrm{termination} \mathrm{reaction;} \mathrm{the}$ color was developed with $0.35 \mathrm{~mL}$ of iodinated solution (here calculated by adding $0.5 \mathrm{~mL}$ of iodinated solution to $10 \mathrm{~mL}$ of reaction solution), and the optical density value was measured at $\mathrm{OD}_{660 \mathrm{~nm}}$ after $10 \mathrm{~min}$, with the non-water bath heating as the control. SBE enzyme activity was expressed as the percentage of decreased $\mathrm{OD}_{660 \mathrm{~nm}}$.

\section{Determination of the activity of key enzymes for protein synthesis in wheat grains}

Key enzymes for protein synthesis include glutamyl ammonia synthase (GS) and glutamate synthase (NADH-GOGAT). Determination of glutamine synthase GS activity by reference to Wang Yuefu's method (Wang et al., 2002). The determination of activity of NADH-GOGAT refers to Wang Xiaochun's method (Wang et al., 2005). The steps of these methods are optimized as follows.

\section{Determination of $G S$}

The wheat seeds were placed in a mortar, liquid nitrogen grinding to powder grinding; transferred to the centrifugal tube, add right amount extraction buffer, $15000 \mathrm{r} / \mathrm{min}$ under $4{ }^{\circ} \mathrm{C}$ centrifugal $20 \mathrm{~min}$, supernatant fluid is the thick enzyme fluid; in $1.6 \mathrm{~mL}$ reaction mixture $\mathrm{B}, 0.7 \mathrm{~mL}$ crude enzyme solution and $0.7 \mathrm{~mL}$ ATP solution were added and mixed; $37^{\circ} \mathrm{C}$ under thermal insulation $0.5 \mathrm{~h}$, adding chromogenic agent (0.2 M TCA, $0.37 \mathrm{M} \mathrm{FeCl} 3$ and $0.6 \mathrm{M} \mathrm{HCl}$ mixture) $1 \mathrm{~mL}$, shake and placed after a while; the supernatant was centrifuged at $5000 \mathrm{r} / \mathrm{min}$ for $15 \mathrm{~min}$, and the absorbance value at $\mathrm{OD}_{540 \mathrm{~nm}}$ was determined. $1.6 \mathrm{~mL}$ reaction mixture A was added as the control.

\section{Determination of NADH-GOGAT}

The wheat seeds were placed in a mortar, ground with liquid nitrogen until the powder, transferred to a centrifuge tube, and an appropriate amount of extract $(10 \mathrm{mM}$ Tris- $\mathrm{HCl}$ buffer, $\mathrm{pH} 7.6$, containing $1 \mathrm{mM} \mathrm{MgCl} 2,1 \mathrm{mM}$ EDTA and $\beta$-mercaptoethanol $1 \mathrm{mM}) ; 4{ }^{\circ} \mathrm{C}$ under $15000 \times \mathrm{g}$ centrifugal $30 \mathrm{~min}$, on a clear night is the enzyme liquid; the total volume of the reaction mixture was $3 \mathrm{~mL}$ (containing $0.4 \mathrm{~mL} 20 \mathrm{mM} \mathrm{L}$ glutamine, $0.05 \mathrm{~mL} 0.1 \mathrm{mM}$ ketoglutaric acid, $0.1 \mathrm{~mL} 10 \mathrm{mM} \mathrm{KCI}, 0.2 \mathrm{~mL} 3 \mathrm{mM}$ $\mathrm{NADH}$ and $0.5 \mathrm{~mL}$ enzyme solution, the insufficient volume was supplemented by 
$1.75 \mathrm{~mL} 25 \mathrm{mM}$ pH7.6 Tris-HCl buffer; the reaction was initiated by L-glutamine and the extinction value was measured at $\mathrm{OD}_{340 \mathrm{~nm}} 1 \mathrm{~min}$ decreased extinction value was as an enzyme activity unit.

\section{Quantitative real time $R T-P C R(R T-q P C R)$}

15 to 20 seeds of uniform size were frozen and extracted from the seeds using Tiangen plus total plant RNA extraction kit. The total RNA was extracted, the quality of RNA was identified by agarose gel electrophoresis, and the RNA concentration and purity were determined at $260 \mathrm{~nm} / 280 \mathrm{~nm}$. Total RNA is used for the synthesis of the first strand of cDNA. The first strand of cDNA was synthesized by FastQuant RT Kit (With gDNase) and ReverTra Ace qPCR RT Master Mix With gDNA Remover (TIANGEN Biotech (Beijing) Co., Ltd., Beijing, China). The above cDNA was detected by wheat internal reference actin gene primers. Specific Primer 5.0 software was used to design the primers for the experiment (Table 2).

Table 2. The primers for qPCR of related genes (with Primer 5.0 software)

\begin{tabular}{c|c}
\hline The name of the primer & The sequence of the primers (from 5'-3') \\
\hline$A C T I N F 1$ & CCAAGGCGGAGTACGATGAGTCT \\
ACTINR1 & TTCATACAGCAGGCAAGCACCAT \\
$R s R H A 2 b F 1$ & TCCGCTCTTTCTTCCTCCG \\
$R s R H A 2 b R 1$ & CCTCCACGACCAACCAACG \\
$Y T H 311 F 1$ & GCCTTAGACTCCGACGATGC \\
$Y T H 311 R 1$ & CGGATGTTCGGTTGTGAGTAG \\
$Y T H 611 F 1$ & CGAGTGGAGCATGTGGATC \\
$Y T H 611 R 1$ & CGAGAATAGAAATACGGAAGGT \\
$Y T H 1065 F 1$ & CAAGGAACAAGGAGCAAAGAAG \\
$Y T H 1065 R 1$ & CGAAGCCGAGTTGGTGGAT \\
$Y T H 2433 F 1$ & GATCCGTGCTGCAACCG \\
$Y T H 2433 R 1$ & GCCAGTGATTTCTCCTCCC \\
$Y T H 2437 F 1$ & ATCGGTTAAGGTTGGTTGGG \\
$Y T H 2437 R 1$ & TGACGGATACATAGGGAAGGTTG \\
$Y T H 2438 F 1$ & CTGAGCACTACTGACCGCACTT \\
$Y T H 2438 R 1$ & AAGCCACTTTCCTCTGCTGTATCTC \\
$Y T H 2456 F 1$ & GCTTGATCTGCGGGATGACC \\
$Y T H 2456 R 1$ & TGAGCTGCACTCGATGTAGGC \\
$Y T H 2496 F 1$ & AGGATGCTGCCCGTGCTTAT \\
$Y T H 2496 R 1$ & CAGGATGCACAGGGAAGTTGG \\
$Y T H 3039 F 1$ & ACGACGATAGTGCTTGGGATG \\
$Y T H 3039 R 1$ & CTGGACCTTACTTTCTACTGGCTTA \\
\hline
\end{tabular}

\section{Statistical analysis}

The GraphPad Prism 8 was used for statistical analysis and drawing. For comparing results of different treatments, Variance analysis is followed by a post-hoc test in order to determine pairwise differences. Differences were considered significant for $\mathrm{P}<0.05$. 


\section{Results \\ Effect of exogenous RsRHA2b gene on the activity of key enzymes in starch synthesis in the mature stage}

ADPG-PPase is an enzyme that catalyzes the conversion of G-1-P into ADPG (adenosine diphosphate glucose), and ADPG is the direct precondition of starch synthesis. ADPG-PPase is a rate-limiting enzyme for starch synthesis, which plays an important role in regulating starch synthesis and accumulation in grains. The effect of exogenous $R s R H A 2 b$ gene on the key enzyme ADPG of starch synthesis in mature wheat was shown in Figure 1A, after $10 \mathrm{~d}$ of wheat grouting, the activity of ADPG enzyme in transgenic lines was significantly higher than Zhengmai 9023; within 10$20 \mathrm{~d}$ after anthesis, the enzyme activity of ADPG in transgenic lines decreased sharply, but compared with Zhengmai 9023, the enzyme activity of transgenic lines was still higher (10 d, 0.3044/0.0049); from 20 to $30 \mathrm{~d}$ after flowering, the trend of transgenic lines and non-transgenic lines was basically the same; in particular, from 25 to $30 \mathrm{~d}$ after anthesis, both showed an upward trend, but their activity was very low.

The granule bound starch synthase (GBSS) is directly related with amylose synthesis enzyme. Endosperm lacking GBSS enzyme activity contains only amylopectin. As can be seen from Figure 1B, both the transgenic strain wheat and the control group showed only certain activity of GBSS $10 \mathrm{~d}$ after flowering. GBSS activity of transgenic lines gradually increased within the range of 10-25 d after anthesis, reached the highest level at $25 \mathrm{~d}$ after anthesis, and then gradually decreased. The GBSS activity of Zhengmai 9023 increased gradually from 10 to $20 \mathrm{~d}$ after anthesis, and reached the highest level at $20 \mathrm{~d}$ after anthesis. Within 10-25 d after anthesis, GBSS activity of transgenic lines was higher than that of Zhengmai 9023 (25 d, 0.05/0.004). At $30 \mathrm{~d}$ after anthesis, the GBSS activity of transgenic lines was lower than that of Zhengmai 9023. The GBSS activity of transgenic lines 30 days after anthesis and control group was very low. However, the GBSS activity of Zhengmai 9023 was slightly higher than that of the transgenic lines.

Soluble starch synthetase (SSS) exists in free state in endosperm cells of wheat seeds and mainly catalyzes the synthesis of amylopectin. The results (Fig. 1C) showed that the change trend of transgenic lines was basically consistent with that of the control group, and the SSS enzyme activity of transgenic lines was always higher than that of the control group. At $10 \mathrm{~d}$ after anthesis, SSS enzyme activity was the highest in transgenic strains, which was about 3 times of that in control group. Within 10-20 d after anthesis, SSS enzyme activity in transgenic lines and the control group decreased sharply (10 d, 0.03/0.009). At $20 \mathrm{~d}$ after anthesis, SSS enzyme activity in both transgenic lines and the control group was at the lowest level. In the range of 20-30 d, the SSS enzyme activity in the control group gradually increased, while the SSS enzyme activity in the transgenic lines first increased 20-25 d after anthesis $(25 \mathrm{~d}$, $0.02 / 0.008$ ), and then decreased in the range of 25-30 $\mathrm{d}$.

During the whole grouting process, the SBE enzyme activity of transgenic strains was always higher than that of the control group (Fig. 1D). The activity of SBE enzyme in transgenic lines showed a trend of "up-down-up". At $20 \mathrm{~d}$ after anthesis, the activity of SBE enzyme in transgenic lines reached the highest peak (20 d, 1.29/0.338), and then showed a "declining-rising" trend, but the range of declining-rising was small $(30 \mathrm{~d}$, $1.25 / 0.265)$. The SBE enzyme activity in the control group reached the highest peak at $25 \mathrm{~d}$ after anthesis ( $25 \mathrm{~d}, 1.212 / 0.748)$, and then showed a significant decline. 
To sum up, the introduction of exogenous $R s R H A 2 b$ gene in the mature stage can regulate the activities of key enzymes of starch synthesis, such as ADPG, SSS, GBSS and SBE.

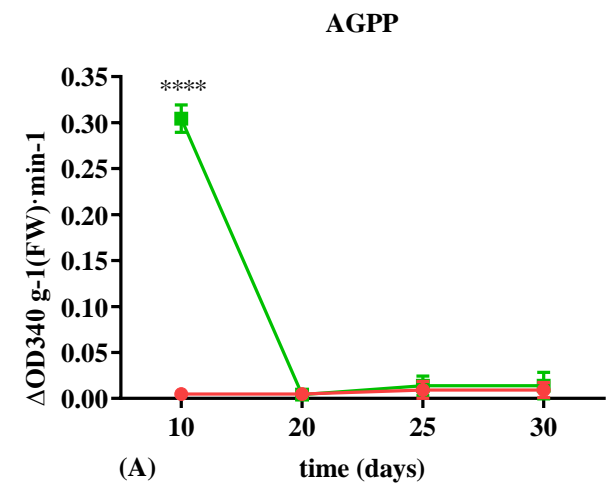

SSS

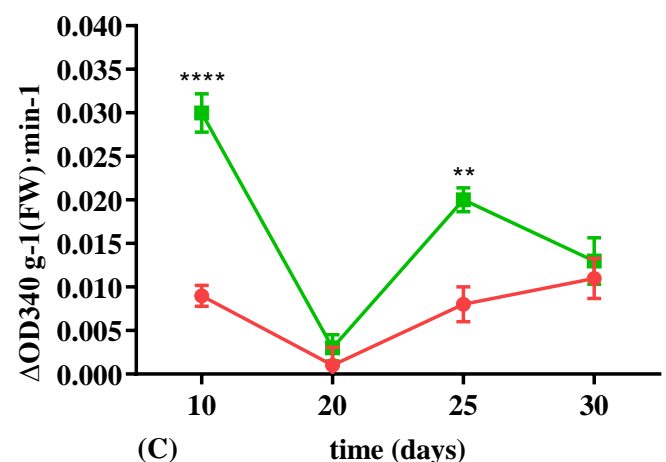

GBSS

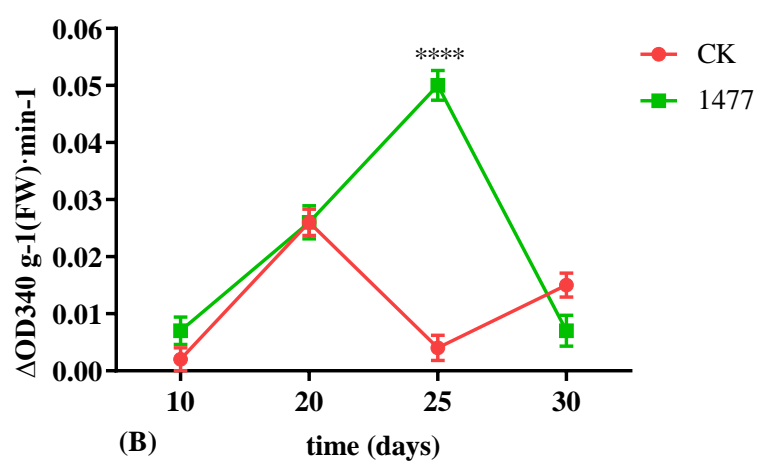

SBE

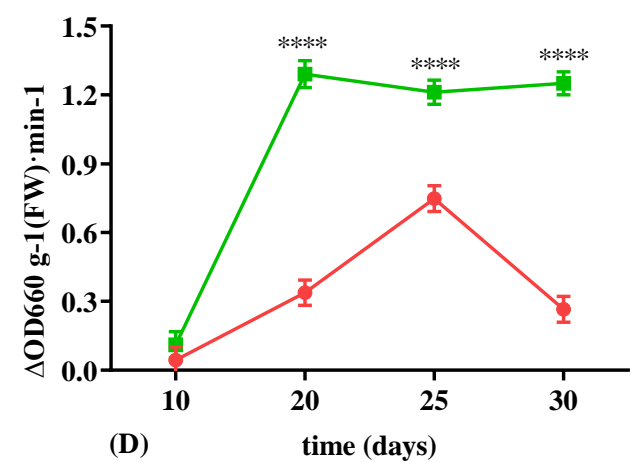

Figure 1. Activity determination of key enzymes of starch synthesis during grain filling stage.

$C K$, Zhengmai9023; 1477, transgenic wheat lines. (A) AGPP, ADPG-Ppase; (B) GBSS, granule-bound starch synthase; (C) SSS, Soluble starch synthase; (D) SBE: starch branching enzyme. Data are expressed as mean values \pm standard errors from three replicates and error bars represent standard errors. The symbol '*' indicates statistically differences $P<0.05$, the symbol '**' indicates statistically differences $P<0.01$, the symbol '***' indicates statistically differences $P<0.001$, the symbol '****' indicates statistically differences $P<0.0001$ (two-way ANOVA, Sidak's multiple comparisons test)

\section{Effect of exogenous RsRHA2b gene introduction on the activity of key enzymes in protein synthesis in wheat maturity stage}

The assimilation of ammonia in plants is mainly through GS/GOGAT pathway. GS is a multi-functional enzyme at the center of nitrogen metabolism, which is involved in a variety of nitrogen metabolism regulation. The improvement of GS activity can enhance the operation ability of nitrogen metabolism and promote the synthesis and transformation of amino acids.

The determination result of GS activity in wheat grain was shown in Figure $2 \mathrm{~A}$. The variation trend of GS content in transgenic lines and the control group was similar, both of which showed a gradually increasing trend with the progress of grouting. However, the activity of GS enzyme in transgenic lines was always lower 
than that in the control group within the range of $10-30 \mathrm{~d}$ after flowering $(30 \mathrm{~d}$, 2.719/3.691).

The determination of GOGAT enzyme activity was shown in Figure $2 B$. The change trend of GOGAT enzyme activity in transgenic lines was similar to that in the control group, and showed a gradually declining trend throughout the grouting period. At 10-25 d after anthesis, the GOGAT enzyme activity of transgenic lines was significantly higher than that of the control group $(10 \mathrm{~d}, 0.2717 / 0.1574 ; 20 \mathrm{~d}$, $0.1887 / 0.0287$ ), while at $30 \mathrm{~d}$ after anthesis, the enzyme activity value of both transgenic lines and the control group decreased to a very low level. To sum up, the introduction of exogenous $R s R H A 2 b$ in the mature stage can regulate the activities of GS and NADH-GOGAT, the key enzymes for protein synthesis in wheat grains.

GS

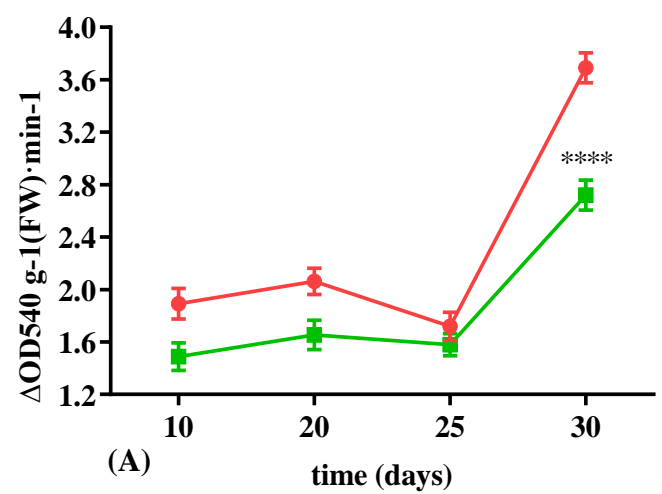

GOGAT

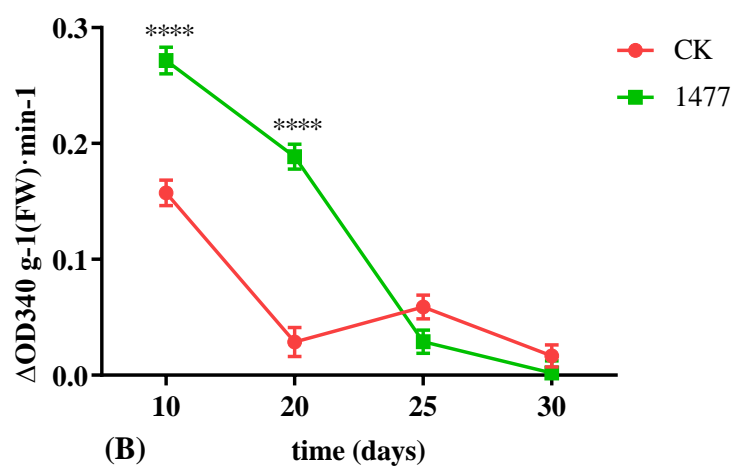

Figure 2. Activity determination of key enzymes of protein synthesis during grain filling stage. CK, Zhengmai 9023; 1477, Transgenic wheat lines; (A) GS, Glutamine synthase; (B) GOGAT, Glutamate synthetase. Data are expressed as mean values \pm standard errors from

three replicates and error bars represent standard errors. The symbol '*' indicates statistically differences $P<0.05$, the symbol '**' indicates statistically differences $P<0.01$, the symbol '***' indicates statistically differences $P<0.001$, the symbol '****' indicates statistically differences $P<0.0001$ (two-way ANOVA, Sidak's multiple comparisons test)

\section{Effect of exogenous RsRHA2b gene introduction on the expression of related genes in the mature stage}

In order to further study the regulatory mechanism of $R s R H A 2 b$ gene in wheat grain starch synthesis and protein synthesis, the exogenous radish gene $R s R H A 2 b$ was introduced into the transgenic lines for experiment in Figure 3. As can be seen from Figure 3, RsRHA2b was almost not expressed in the control group during the whole grain-filling period, since there was no RsRHA2b gene in the control group. In transgenic lines, the relative expression of $R s R H A 2 b$ showed a trend of first increasing and then decreasing, and reached the maximum at $10 \mathrm{~d}$ after anthurium $(10 \mathrm{~d}$, 19.361/1), and then decreased, but was always significantly higher than that of the control group.

The proteins encoded by the 9 genes in this study interacted with RHA2b. The effect of exogenous $R H A 2 b$ gene introduction on the expression of RHA2b interacting protein was studied by using transgenic lines. 


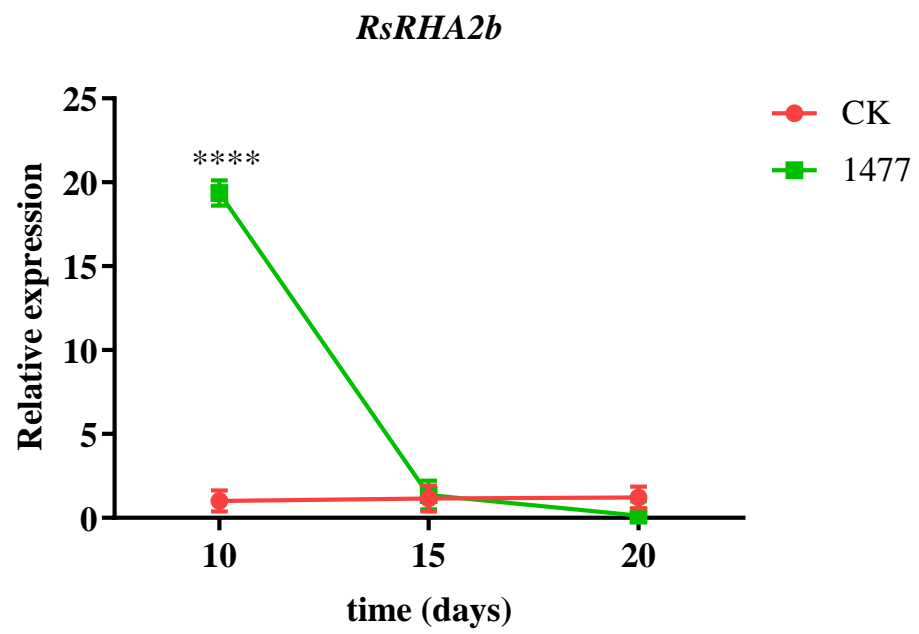

Figure 3. Expression analysis of RsRHA2b gene during grain filling stage. $C K$, Zhengmai 9023; 1477, transgenic wheat lines. Data are expressed as mean values \pm standard errors from three replicates and error bars represent standard errors. The symbol '*' indicates statistically differences $P<0.05$, the symbol '**' indicates statistically differences $P<0.01$, the symbol

'***' indicates statistically differences $P<0.001$, the symbol '****' indicates statistically differences $P<0.0001$ (Two-way ANOVA, Sidak's multiple comparisons test)

\section{YTH311, YTH611 and YTH1065 genes}

As can be seen from Figure 4, in the process of grain formation, the relative expressions of YTH311, YTH611 and YTH1065 in the transgenic lines and the control group all showed a trend of increasing first and then decreasing. The relative expression levels of these three genes in transgenic lines were always higher than those in the control group. From 10 to $15 \mathrm{~d}$ after anthesis, the relative expressions of these three genes in transgenic lines and the control group showed an increasing trend. At $15 \mathrm{~d}$ after anthesis, the relative expression levels of the three genes in the transgenic lines and the control group reached the highest. The highest relative expression of YTH311 gene (Fig. 4A) in transgenic and control groups was 1.2/0.7 (15 d), the highest relative expression of YTH611 gene (Fig. 4B) was 7.5/2.5 (15 d), and the highest relative expression of YTH1065 gene (Fig. 4C) was 10/3 (15 d), respectively. The relative expression levels of the three genes in the transgenic lines decreased about 15-20 d after flowering. The results showed that the introduction of exogenous $R s R H A 2 b$ in the mature stage affected the expression of YTH311, YTH611 and YTH1065.

\section{YTH2433 gene}

As can be seen from Figure 4D, the relative expression of YTH2433 gene in transgenic lines and the control group both decreased first and then increased during the whole grain filling period $(10 \mathrm{~d}, 1.5 / 4.46)$. At $15 \mathrm{~d}$ after anthesis, there was no significance between the relative expression level of $Y T H 2433$ gene in both control group and transgenic lines. At $20 \mathrm{~d}$ after anthesis, the relative expression level of YTH2433 gene in the control group was lower than that in the transgenic lines $(20 \mathrm{~d}$, 1.07/3.35). The introduction of exogenous RsRHA2b in the mature stage affected the expression of $Y T H 2433$. 

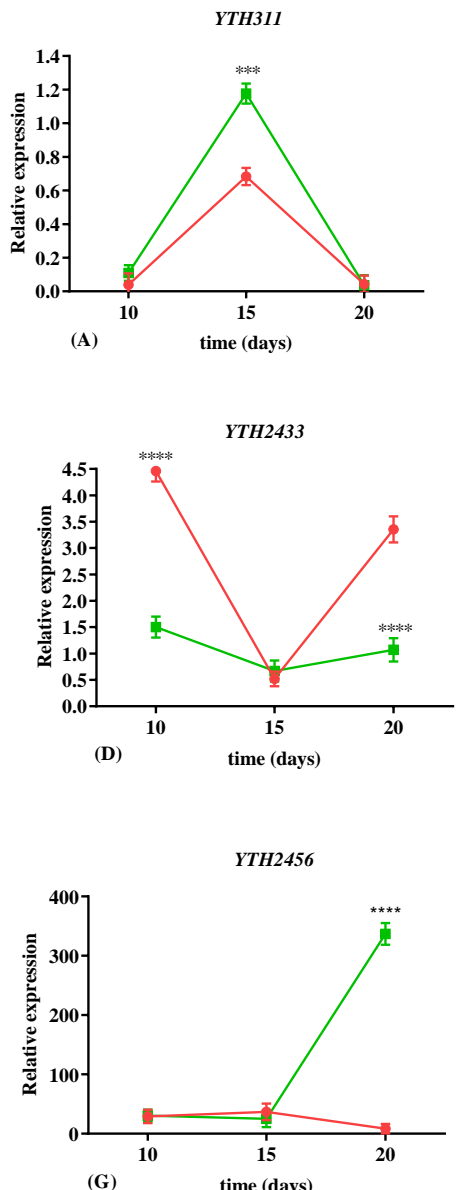
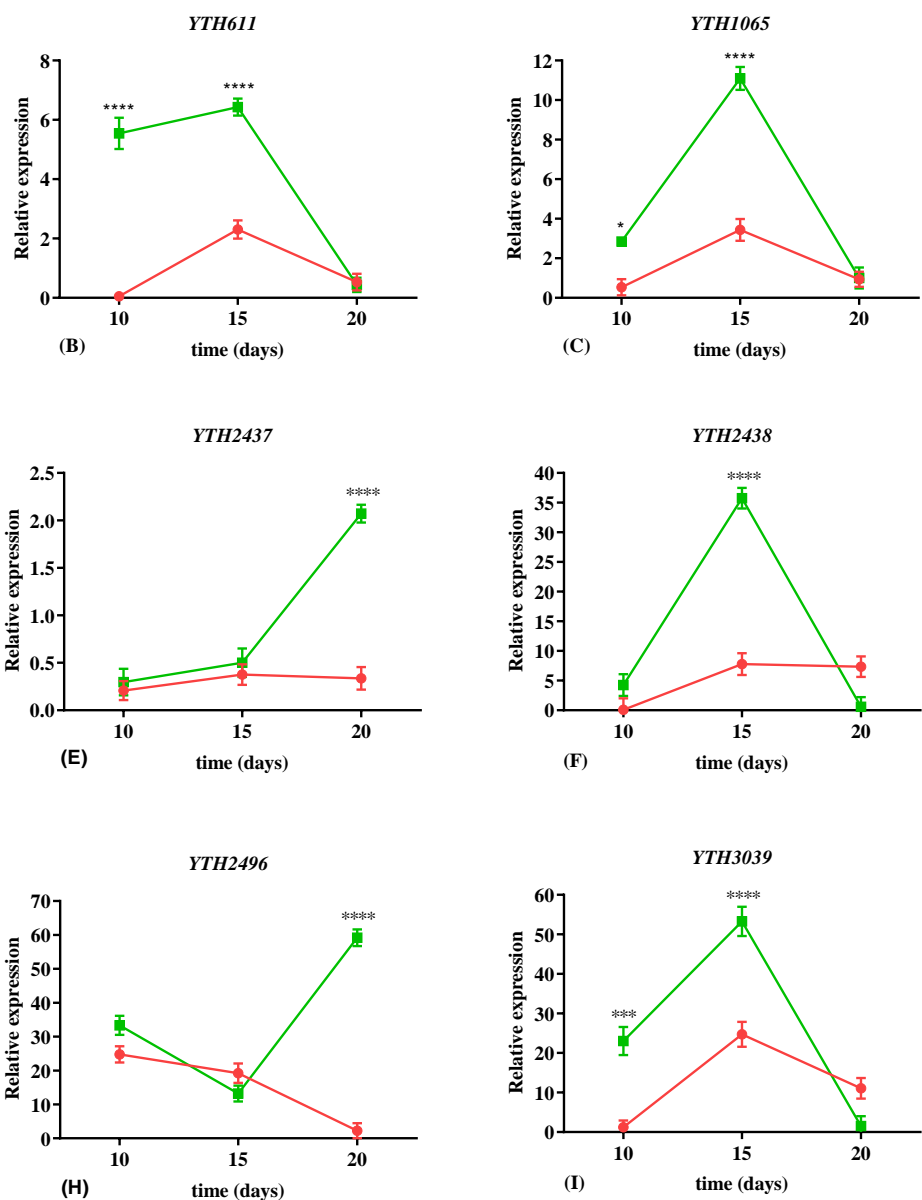

Figure 4. Expression analysis of candidate genes during grain filling stage. $C K$, Zhengmai 9023; 1477, transgenic wheat lines. (A) YTH311; (B) YTH611; (C) YTH1065; (D) YTH2433; (E) YTH2437; (F) YTH2438; (G) YTH2456; (H) YTH2496, (I) YTH3039. Data are expressed as mean values \pm standard errors from three replicates and error bars represent standard errors. The symbol '*' indicates statistically differences $P<0.05$, the symbol '**' indicates statistically differences $P<0.01$, the symbol '***' indicates statistically differences $P<0.001$, the symbol '****' indicates statistically differences $P<0.0001$ (two-way ANOVA, Sidak's multiple comparisons test)

\section{YTH2437 gene}

The relative expression of $Y T H 2437$ gene in transgenic lines and the control group showed an increasing trend during the whole grain filling period (Fig. 4E). The expression of $Y T H 2437$ gene in transgenic lines was higher than that in control lines, and reached a significant level at $20 \mathrm{~d}$ after anthesis $(25 \mathrm{~d}, 2.071 / 0.337)$. The introduction of exogenous $R s R H A 2 b$ in the mature stage affected the expression of YTH2437.

\section{YTH2456 and YTH2496 genes}

The relative expression levels of YTH2456 (Fig. 4G) and YTH2496 (Fig. 4H) in transgenic lines both decreased first and then increased in the process of grain formation, while the relative expression levels of these two genes in the control group 
both showed a trend of continuous decrease. However, there was no significance between the relative expression of these two genes in the control group and the transgenic lines at 10 and 15 days after flowering. At $20 \mathrm{~d}$ after anthesis, the relative expression levels of these two genes in transgenic lines were higher than those in the control group (20 d, 336.695/8.619, YTH2456; $20 \mathrm{~d}, 59.171 / 2.217$, YTH2496). The results showed that the introduction of exogenous $R s R H A 2 b$ in the mature stage affected the expression of YTH2456 and YTH2496 genes.

\section{YTH2438 and YTH3039 genes}

The relative expressions of YTH2438 (Fig. 4F) and YTH3039 (Fig. 4I) in transgenic lines showed a trend of first rising and then falling in the process of grain formation. However, at $10 \mathrm{~d}$ and $15 \mathrm{~d}$ after anthesis, the relative expression levels of these two genes in transgenic lines were significantly higher than those in the control group $(10 \mathrm{~d}$, 23.022/1.245, YTH3039; 15 d, 37.742/7.799, YTH2438; 15 d, 53.284/24.743, YTH3039). However, there was no significance between the relative expressions of these two genes in the control group and the transgenic lines at $20 \mathrm{~d}$ after flowering. The introduction of exogenous $R s R H A 2 b$ in the mature stage affected the expression of YTH2438 and YTH3O39.

\section{Discussion}

The regulatory network of a series of proteins interacting with RHA2b involves the processes of protein ubiquitination, cell protein metabolism, low temperature tolerance, and response to water loss, $\mathrm{ABA}$, acidic compounds, oxygen-containing compounds and abiotic stress (Jiang et al., 2009; Kurkela and Franck, 1990; Li et al., 2011; Usadel et al., 2008; Nelson et al., 2010; Stone, 2014; Cho et al., 2011; Zheng et al., 2012; Robinson et al., 2010; Sajan et al., 2007; Haynes et al., 2002).

A series of RHA $2 b$ interacting proteins were selected by yeast two hybridization. In screening these proteins, the library is ABA treated, so the focus of the study will be on the ABA signaling pathway, or the signaling pathway indirectly mediated by ABA. Bioinformatics analysis showed that the protein encoded by YTH311 gene may belong to SBE amylase, which is important for starch synthesis in the late endosperm development (Morell et al., 1995). The protein encoded by YTH2456 gene may belong to RACD protein and participate in different signal transduction pathways through RAC/ROP (Schultheiss et al., 2003). The protein encoded by YTH2496 gene may belong to AP2/EREBP protein, which is involved in development and abiotic stress (Jofuku et al., 1994; Ohmetakagi and Shinshi, 1995). The properties of these genes confirm the diversity of protein action.

Considering from the view that wheat with exogenous $R s R H A 2 b$ gene can enhance the ability of ear germination, and the ability of ear germination is mainly affected by dormancy. Should be Does this focus on increased seed dormancy in transgenic wheat? How to enhance?

Dormancy of wheat seeds includes two types: embryo dormancy and seed (fruit) skin dormancy. The author speculated that seed coat dormancy caused by exogenous $R s R H A 2 b$ gene can be easily reflected by seed size, maturity and internal restraining substance. If the dormancy is caused by the embryo, it will be affected by the expression of specific genes, as well as the metabolism and activity of specific nutrients. Because embryo dormancy can also be regulated by hormones. Decreased ABA content 
promoted germination (King, 1976). Therefore, if the introduction of exogenous genes affects the metabolic pathway of specific hormones, it can also change the ability to resist ear germination.

A large number of studies have shown that the key enzymes in the starch anabolism process, such as AGPP, GBSS, SSS and SBE, play a key role in the synthesis and accumulation of wheat starch (Okita, 1992; Keeling et al., 1988; Nakamura et al., 1993). Protein content, protein components content and proportion not only affect the nutritional quality of wheat, but also have a great influence on the processing quality of wheat (Zhu and Khan, 2001). In addition to ensuring the integration and inheritance of exogenous genes, it is better not to change the biological environment and genetic background of recipient materials in the application of transgenic technology in the improvement of crop varieties. It was found that transgenic materials could not only improve the target traits, but also induce some non-target traits.

In the present study, it was found that the introduction of exogenous $R s R H A 2 b$ could positively regulate the activities of the key enzyme for wheat starch synthesis AGPP, GBSS, SSS, SBE and the key enzyme of protein synthesis NADH-GOGAT in the process of grain filling, and only inhibited the activities of the key enzyme of protein synthesis GS. This indicated that the synthesis of wheat protein was greatly affected by the activity of GOGAT enzyme in the grain, but less by the activity of GS enzyme. This indicates that the complex formed by RHA2b and candidate protein may mediate some important regulatory pathways in the metabolism of carbon and nitrogen, change the metabolism of specific nutrients, and thus improve the resistance to ear germination of transgenic materials.

The results of this experiment showed that the introduction of exogenous RsRHA2b gene did affect the influence of related genes. The introduction of exogenous RsRHA2b promoted the expression of YTH311, YTH611, YTH1065, YTH2437, YTH2438, YTH2456, YTH2496 and YTH3049, and inhibited the expression of YTH2433. This indicates that the complex formed by RHA and candidate protein may mediate some important regulatory networks of hormone response, play a role on specific pathway sites, and then affect the spike germination characteristics of transgenic materials.

\section{Conclusion}

The present research revealed that the introduction of exogenous $R s R H A 2 b$ increased the activity of AGPP, GBSS, SSS, SBE and GOGAT, and decreased the activity of GS. Exogenous RsRHA2b promoted the expression of YTH311, YTH611, YTH1065, YTH2437, YTH2438, YTH2456, YTH2496 and YTH3049, and inhibited the expression of $Y T H 2433$. More work is needed to explore the regulation of RsRHA2b gene on transgenic wheat grain quality and its mechanism as follows: (1) $\alpha$-amylase activity, amylopectin activity and starch content of transgenic lines; (2) sulfhydryl content of stored proteins; (3) determination and analysis of quality related indicators, such as gelatinization properties of starch, flour farinograms and tensile parameters.

Acknowledgements. This work was supported by the "Twelfth Five-Year" National Science and Technology Projects in Rural Areas (2013BADD04B01-02) and Henan Science and Technology Project (162102110007).

Conflict of interests. The authors state no conflict of interests. 


\section{REFERENCES}

[1] Baroja-Fernández, E., Muñoz, F. J., Saikusa, T., Rodríguez-López, M., Akazawa, T., Pozueta-Romero, J. (2003): Sucrose synthase catalyzes the de novo production of ADPglucose linked to starch biosynthesis in heterotrophic tissues of plants. - Plant and Cell Physiology 44: 500-509.

[2] Cheng, F., Jiang, D., Wu, P., Shi, C. (2001): The dynamic change of starch synthesis enzymes during the grain filling stage and effects of temperature upon it. - Acta Agronomica Sinica 27: 201-206.

[3] Cho, S. K., Ryu, M. Y., Seo, D. H., Kang, B. G., Kim, W. T. (2011): The arabidopsis RING E3 ubiquitin ligase AtAIRP2 plays combinatory roles with AtAIRP1 in abscisic acid-mediated drought stress responses. - Plant Physiology 157: 2240-2257.

[4] Emes, M. J., Bowsher, C. G., Hedley, C., Burrell, M. M., Scrase-Field, E. S. F., Tetlow, I. J. (2003): Starch synthesis and carbon partitioning in developing endosperm. - Journal of Experimental Botany 54: 569-575.

[5] Haynes, C. M., Caldwell, S. R., Cooper, A. A. (2002): An HRD/DER-independent ER quality control mechanism involves Rsp5p-dependent ubiquitination and ER-Golgi transport. - Journal of Cell Biology 158: 91-102.

[6] Jiang, H., Li, H., Bu, Q., Li, C. (2009): The RHA2a-interacting proteins ANAC019 and ANAC055 may play a dual role in regulating ABA response and jasmonate response. Plant Signaling \& Behavior 4: 464-466.

[7] Jofuku, K. D., Den Boer, B. G. W., Van Montagu, M., Okamuro, J. K. (1994): Control of Arabidopsis flower and seed development by the homeotic gene APETALA2. - The Plant Cell 6: 1211-1225.

[8] Keeling, P. L., Wood, J. R., Tyson, R. H., Bridges, I. G. (1988): Starch biosynthesis in developing wheat grain evidence against the direct involvement of triose phosphates in the metabolic pathway. - Plant Physiology 87: 311-319.

[9] King, R. (1976): Abscisic acid in developing wheat grains and its relationship to grain growth and maturation. - Planta 132: 43-51.

[10] Kurkela, S., Franck, M. (1990): Cloning and characterization of a cold-and ABAinducible Arabidopsis gene. - Plant Molecular Biology 15: 137-144.

[11] Li, D., Lyu, G., Lyu, J., Niu, H., Wang, X., Jun, Y. (2019): Cloning and characterization of a wheat RING finger gene TaRHA2b whose expression is up-regulated by ABA treatment. - Applied Ecology and Environmental Research 17: 7495-7510.

[12] Li, H., Jiang, H., Bu, Q., Zhao, Q., Sun, J., Xie, Q., Li, C. (2011): The arabidopsis RING finger E3 ligase RHA2b acts additively with RHA2a in regulating abscisic acid signaling and drought response. - Plant Physiology 156: 550-563.

[13] Li, T., Shen, B., Chen, N., Luo, Y. (1997): Effect of Q-enzyme on the chalkiness formation of rice grain. - Acta Agronomica Sinica 23: 338-344.

[14] Li, Y., Yu, Z., Jiang, D., Yu, S. (2001): Studies on the dynamic changes of the synthesis of sucrose in the flag leaf and starch in the grain and related enzymes of high-yielding wheat. - Acta Agronomica Sinica 27: 658-664.

[15] Morell, M. K., Rahman, S., Abrahams, S., Appels, R. (1995): The biochemistry and molecular biology of starch synthesis in cereals. - Australian Journal of Plant Physiology 22: 647-660.

[16] Nakamura, T., Yamamori, M., Hirano, H., Hidaka, S. (1993): Decrease of waxy (Wx) protein in two common wheat cultivars with low amylose content. - Plant Breeding 111: 99-105.

[17] Nakamura, Y., Yuki, K., Park, S.-Y., Ohya, T. (1989): Carbohydrate metabolism in the developing endosperm of rice grains. - Plant and Cell Physiology 30: 833-839.

[18] Nelson, D. C., Flematti, G. R., Riseborough, J., Ghisalberti, E. L., Dixon, K. W., Smith, S. M. (2010): Karrikins enhance light responses during germination and seedling 
development in Arabidopsis thaliana. - Proceedings of the National Academy of Sciences of the United States of America 107: 7095-7100.

[19] Ohmetakagi, M., Shinshi, H. (1995): Ethylene-inducible DNA binding proteins that interact with an ethylene-responsive element. - The Plant Cell 7: 173-182.

[20] Okita, T. W. (1992): Is there an alternative pathway for starch synthesis. - Plant Physiology 100: 560-564.

[21] Pan, Q., Yu, Z. (2002): Effects of nitrogen topdressing stage on grain quality and yield of winter wheat. - Journal of Triticeae Crops 22: 65-69.

[22] Robinson, T. J., Dinan, M. A., Dewhirst, M. W., Garciablanco, M. A., Pearson, J. L. (2010): SplicerAV: a tool for mining microarray expression data for changes in RNA processing. - BMC Bioinformatics 11: 108-108.

[23] Sajan, S. A., Warchol, M. E., Lovett, M. (2007): Toward a systems biology of mouse inner ear organogenesis: gene expression pathways, patterns and network analysis. Genetics 177: 631-653.

[24] Schultheiss, H., Dechert, C., Kogel, K.-H., Hückelhoven, R. (2003): Functional analysis of barley RAC/ROP G-protein family members in susceptibility to the powdery mildew fungus. - The Plant Journal 36: 589-601.

[25] Stone, S. L. (2014): The role of ubiquitin and the 26S proteasome in plant abiotic stress signaling. - Frontiers in Plant Science 5: 135-135.

[26] Usadel, B., Blaesing, O. E., Gibon, Y., Retzlaff, K., Hoehne, M., Guenther, M., Stitt, M. (2008): Global transcript levels respond to small changes of the carbon status during progressive exhaustion of carbohydrates in arabidopsis rosettes. - Plant Physiology 146: 1834-1861.

[27] Wang, H., Ma, C., Xu, F., Andong, W. (2001): Effect of heat-treatment on endersperm protein components of wheat. - Journal of Triticeae Crops 21: 64-66.

[28] Wang, X., Xiong, S., Ma, X., Zhang, J., Wang, Z. (2005): Effects of different nitrogen forms on key enzyme activity involved in nitrogen metabolism and grain protein content in speciality wheat cultivars. - Acta Ecologica Sinica 25: 802-807.

[29] Wang, Y., Yu, Z., Li, S., Yu, S. (2002): Effect of nitrogen nutrition on the change of key enzyme activity during the nitrogen metabolism and kernel protein content in winter wheat. - Acta Agronomica Sinica 28: 743-748.

[30] Wang, Y., Yu, Z., Li, S., Yu, S. (2003): Activity of enzymes related to starch synthesis and their effect during the filling of winter wheat. - Acta Agronomica Sinica 29: 75-81.

[31] Yang, J., Zhang, J., Wang, Z., Xu, G., Zhu, Q. (2004): Activities of key enzymes in sucrose-to-starch conversion in wheat grains subjected to water deficit during grain filling. - Plant physiology 135: 1621-1629.

[32] Zhao, J., Yu, Z., Huimin;, S., Xinghua;, M., Qiang, S. (2004): Differences in starch components and related enzymes activity in the grains of different wheat cultivars. - Acta Agronomica Sinica 30: 525-530.

[33] Zheng, Y., Schumaker, K. S., Guo, Y. (2012): Sumoylation of transcription factor MYB30 by the small ubiquitin-like modifier E3 ligase SIZ1 mediates abscisic acid response in Arabidopsis thaliana. - Proceedings of the National Academy of Sciences of the United States of America 109: 12822-12827.

[34] Zhu, J., Khan, K. (2001): Effects of genotype and environment on glutenin polymers and breadmaking quality. - Cereal Chemistry 78: 125-130. 